\title{
Incidence of Refeeding Syndrome and Its Associated Factors in South African Children Hospitalized with Severe Acute Malnutrition
}

\author{
Audrey Philisiwe Mbethe, ${ }^{1, *}$ and Siyazi $\mathrm{Mda}^{2}$ \\ ${ }^{1}$ MBChB, FC Paed with Colleges of Medicine of South Africa, Paediatric registrar at Department of Paediatrics and Child Health, Sefako Makgatho Health Sciences University, \\ Pretoria, South Africa \\ ${ }^{2}$ MBChB, MMed: Paediatrics, PhD, Professor and Senior Lecturer, Department of Paediatrics and Child Health, Sefako Makgatho Health Sciences University, Pretoria, South \\ Africa \\ "Corresponding author: Audrey Philisiwe Mbethe, Sefako Makgatho Health Sciences University, Pretoria, South Africa. Fax: +27-125213627, E-mail: audreymbethe@yahoo.com
} Received 2016 August 14; Revised 2017 January 08; Accepted 2017 February 05.

\begin{abstract}
Background: The judicious use of the world health organization (WHO) guidelines in the management of severe acute malnutrition (SAM) is very crucial in avoiding complications. We investigated the incidence of refeeding syndrome and its associated factors in children under 5 years with SAM receiving treatment as inpatients.

Methods: A prospective study of 104 children with SAM admitted to the paediatric unit of Dr George Mukhari Academic Hospital (a teaching hospital in Pretoria, South Africa) since March 2014 to March 2015 was conducted. On admission, history on socioeconomic status and co-morbidities, a comprehensive clinical examination, and anthropometric measurements were obtained. All the patients were managed using the 10 steps of management of malnutrition with cautious feeding and broad spectrum antibiotics being instituted. Bloods were taken for calcium, magnesium, phosphorous, urea, and electrolytes on admission and compared to repeat bloods done on day 5 post admission.

Results: There were a total of 46 (44\%) females. The mean age was 16 months with a mean weight-for-height Z-score of $-2.15 \pm 1.87$. The majority 63\% (63/104) of the children had oedematous SAM. There was an HIV infection rate of 33\% (35/104). The incidence of refeeding syndrome was 16/104 (15\%). Refeeding syndrome was strongly associated with the following medical complications: diarrhoea $81 \%$ (13/16), shock 25\% (4/16), and hypokalaemia 81\% (13/16) (P value < 0.01). Admission potassium and phosphorus were strongly associated with refeeding syndrome with a mean of $3.04 \pm 1.16$ for potassium and $1.14 \pm 0.39$ for phosphate (P value $<$ 0.05). Refeeding syndrome was also strongly associated with hypophosphataemia ( $0.65 \pm 0.28)$, hypocalcaemia (2.34 \pm 0.24$)$, and hypomagnesaemia $(0.91 \pm 0.52)$ on day 5 repeat bloods ( $P$ value $<0.0001)$.

Conclusions: The complication of refeeding syndrome is a major problem that occurs with the reintroduction of feeding in children with severe acute malnutrition. This detrimental complication can be avoided by practices that promote cautious feeding, and as well, clinicians being vigilant in detecting the complication in all children with severe acute malnutrition.
\end{abstract}

Keywords: Severe Acute Malnutrition, Refeeding Syndrome, Hypophosphataemia, Medical Complications

\section{Background}

The term severe acute malnutrition replaces the old terminology of marasmus and kwashiorkor. Severe acute malnutrition (SAM) should be diagnosed if a child has one of the following features: weight-for-height Z-score below -3 , visible wasting, a mid-upper-arm-circumference $<11.5$ $\mathrm{cm}$ (at 6 months to 5 years of age), and nutritional oedema (1). It is estimated that 20 million children around the world have SAM and it contributes to approximately 1.5 million preventable deaths each year $(2,3)$. SAM was estimated to occur in 13 million (9\% of all children under 5 years of age) children in Sub-Saharan Africa in 2012 (4). The incidence of SAM in South Africa was 5\% in 2010 (5, 6), and the mortality rate amongst the hospitalized South African children with SAM was 20\% to 30\% in 2012 (7).

The medical complications of SAM include the follow- ing: diarrhoea with poor capillary refill, lethargy, hypoglycaemia, hypokalaemia, pneumonia, sepsis or bacteraemia, obvious anaemia, weeping dermatoses, and hepatomegaly $>4 \mathrm{~cm}$ (8). In the management of SAM, children are given food that contains both protein and energy. One would intuitively want to start on a high protein and high energy diet due to the deficit that these children have, but this is detrimental and may result in the development of refeeding syndrome (9).

Refeeding syndrome is a potentially fatal complication of the nutritional management of children with SAM which is partly related to the type of formula used (10). Refeeding syndrome culminates in shifts in fluids and electrolytes resulting from humoral and metabolic changes; these shifts in fluids and electrolytes may cause serious clinical complications. The hallmark biochemical change of the refeeding syndrome is hypophosphataemia,

Copyright (c) 2017, Iranian Journal of Pediatrics. This is an open-access article distributed under the terms of the Creative Commons Attribution-NonCommercial 4.0 International License (http://creativecommons.org/licenses/by-nc/4.0/) which permits copy and redistribute the material just in noncommercial usages, provided the original work is properly cited. 
but there can be accompanying hypokalaemia, hypocalcaemia, and changes in fat and protein metabolism (11).

The true incidence of refeeding syndrome in children with SAM is unknown as there is a paucity of studies in this population. Refeeding syndrome has been observed in adults who have had long periods of starvation (eg, anorexia nervosa and malabsorptive syndromes) with an incidence rate of $10 \%$ (12). In a study in which adolescents with anorexia nervosa were evaluated, the incidence of refeeding syndrome was noted to be $6 \%$ (13). In a study conducted in 2012 that assessed refeeding syndrome in Indian children with coeliac disease, an incidence of $14 \%$ was observed (14).

Patients at an increased risk of developing the refeeding syndrome include those with kwashiorkor, marasmus, and acute weight loss of $>10 \%$ in the previous two months and chronic conditions causing malnutrition and malabsorptive syndromes $(15,16)$. Since there is a paucity of studies that have assessed refeeding syndrome in children, the authors designed a study to assess the incidence of refeeding syndrome in children with SAM and the risk factors associated with the syndrome.

\section{Methods}

In an observational study, children who had been hospitalized at Dr George Mukhari Academic Hospital with SAM (as per diagnostic criteria) were sequentially enrolled by the principal researcher within 24 hours of admission. This hospital is the teaching hospital for the Sefako Makgatho Health Sciences University, and is located in Pretoria, the administrative capital of the republic of South Africa.

Inclusion criteria: all children with SAM whose parents/guardians had provided written informed consent.

Exclusion criteria: children with a chronic illness that might have predisposed them to the development of the refeeding syndrome.

The principal researcher obtained history from the children's primary caregivers and, also, conducted a comprehensive clinical examination. The information that was obtained from history included the following: maternal age, the level of education and employment status of the mother, the type of housing and sanitation, and a history of TB contact. In addition to these, each patient's date of birth and date of hospitalization was noted and these were used to calculate the age of each child.

The children's weights and heights were measured by the principal researcher, while length was measured by the principal researcher with the help of an assistant. Each child's weight was measured using a single calibrated scale with the child only wearing a clean nappy or underwear approximated to the nearest 0.1 kilogram (kg) (17). Length was measured in all children younger than 2 years using a measuring board with a fixed upper part and a movable lower part. The child was placed in the supine position with the head against the fixed upper part of the board. The principal researcher ensured that the knees were straight and the arms were next to the torso, while the assistant placed the bottom movable part against the child's flat feet as per validated procedures (17). Height was measured in all children over 2 years with the child standing upright against a stadiometer according to standardized procedures (17). Both height and length were approximated to the nearest 0.1 centimetre $(\mathrm{cm})$.

The mid-upper-arm-circumference (MUAC) was, also, measured by the principal researcher using the WHO colour-coded measuring bands (17).

All the enrolled children were assessed for oedema and medical complications of SAM which included diarrhoea, hypothermia, obvious anaemia, hypokalaemia, and hypoglycaemia. Children with a glucose value below 2.6 $\mathrm{mmol} / \mathrm{L}$ were assessed as being hypoglycaemic (7). Additionally, blood samples were obtained (within 24 hours of hospitalization) for sodium, potassium, urea, creatinine, full blood count, C-reactive protein, and blood culture. As the culminant feature of refeeding syndrome is hypophosphatemia, blood levels for calcium, magnesium, and phosphate (CMP) were, also, sampled within 24 hours of hospitalization.

All the children were treated according to the 10 steps of malnutrition including feeding with F75 $(9,18)$. A detailed description of the management of the children in the study is shown in Appendix 1 in the Supplementary File. All the children were, also, investigated for tuberculosis.

All the children were reviewed by the attending physician and by the principal researcher at least once a day. On the fifth day of hospitalization, blood samples for urea, sodium, and potassium, and for calcium, magnesium, and phosphate were obtained. The results of these were then compared with the results of the samples obtained on admission. The progress of all the children was monitored until their discharge from hospital or their demise.

Ethical clearance was obtained from the Institutional Review Board prior to the commencement of data collection.

\subsection{Statistical Analysis}

It was intended to enrol 138 patients based on sample size calculations ( $80 \%$ power and $5 \%$ significance level) using the formula $\mathrm{n}=\mathrm{Z}^{2} \times \mathrm{P}(1-\mathrm{P}) / \mathrm{e}^{2}$, where $\mathrm{z}=1.96$ for $95 \%$ confidence interval and $\mathrm{P}=0.1$ (assuming an incidence rate of $10 \%$ ) and e $=0.05$ significance level. However, after 104 children had been enrolled, there were no hospitalized 
children with SAM for several weeks. The researchers then decided to analyse the available data.

Data were assessed for normality by visual examination of distribution plots followed by normality tests. Statistical analysis was done using the IBM SPSS Statistics 23. Descriptive statistics including frequencies and mean and standard deviation were used for anthropometric data, incidence, and complications, respectively.

Anthropometric measurements, serum sodium, potassium, calcium, magnesium, and phosphate levels were compared between the two groups (those who developed refeeding syndrome and those who did not) using the independent t-test. The chi-square test was used to compare the frequency of medical complications and other categorical variables between the two groups. Within group comparison of biochemical indices on admission and on the fifth day of hospitalization was conducted by means of the paired t-test.

\section{Results}

A total of 104 children were enrolled over a 1 year period, since March 2014 to March 2015. The mean age of the 104 children was 16 months with the youngest being 4.4 months and the oldest 49.5 months. Refeeding syndrome developed in 16 of the 104 enrolled children, thus giving an incidence of $15 \%$. There were 58 (56\%) males and there was no difference in the proportion of males between children who developed refeeding syndrome and those who did not develop the syndrome. Children who developed refeeding had similar means for weight and height compared with the ones who did not develop the syndrome. Among all the enrolled children, 69 (67\%) of them were HIV negative. The age, gender, and anthropometric indices of the enrolled children are shown in Table 1 and are compared by the presence or absence of refeeding syndrome.

There was no difference in the weight-for-age, and weight-for-height Z-scores between children who developed refeeding syndrome and those who did not. Mean weight-for-age Z-scores were below -3 in both groups of children (those who developed refeeding and those who did not develop it). The mean height-for-age Z-score was slightly lower in the non-refeeding group than that in the group of children who acquired the refeeding syndrome. The weight-for-height Z-scores were between -2 and -3 in both groups of children. The mortality rate for all enrolled children was $9.5 \%$ and the majority of the children who died had develop refeeding syndrome.

In Table 2, children who developed refeeding syndrome are compared with those who did not, using the diagnostic criteria for SAM.
Table 1. Age, Gender, and Anthropometric Indices of All the Children ${ }^{\mathrm{a}, \mathrm{b}}$

\begin{tabular}{lccc}
\hline & Refeeding Syndrome & Non-Refeeding & All Children \\
\hline Total & $16(15)$ & $88(85)$ & 104 \\
Female & $9(56)$ & $37(42)$ & $46(44)$ \\
\hline Age, mo & $15.02 \pm 6.51$ & $16.28 \pm 8.14$ & $16.04 \pm 7.86$ \\
\hline Weight, kg & $6.47 \pm 1.53$ & $6.93 \pm 1.67$ & $6.87 \pm 1.65$ \\
\hline Height, cm & $70.81 \pm 6.56$ & $70.38 \pm 8.99$ & $70.49 \pm 8.60$ \\
WAZ & $-3.48 \pm 1.51$ & $-3.42 \pm 1.48$ & $-3.43 \pm 1.48$ \\
\hline HAZ & $-2.52 \pm 3.15$ & $-3.05 \pm 2.53$ & $-2.97 \pm 2.62$ \\
\hline WHZ & $-2.65 \pm 2.35$ & $-2.06 \pm 1.78$ & $-2.15 \pm 1.87$ \\
\hline MUAC, cm & $12.22 \pm 1.54$ & $11.78 \pm 2.05$ & $12.02 \pm 1.45$ \\
\hline HIV positive & $7(43.8)^{\mathrm{c}}$ & $28(32)$ & $35(33.3)$ \\
\hline Mortality & $1(6)$ & $9(10)$ & $10(9.5)$ \\
\hline
\end{tabular}

Abbreviations: HAZ, height-for-age Z-score; HIV, Human immunodeficiency virus; MUAC, mid-upper-arm-circumference; $\mathrm{N}$, number; WAZ, weight-for-age Z-score; WHZ, weight-for-height Z-score.

${ }^{\mathrm{a}}$ Values are expressed as mean \pm SD or No. (\%).

${ }^{\mathrm{b}}$ Independent t-test used to compare the two groups except female, HIV positive and mortality (where the chi-square was used).

${ }^{\mathrm{c}}$ Significantly different from the non-refeeding group $(\mathrm{P}<0.01)$

Table 2. WHO Diagnostic Criteria for $\mathrm{SAM}^{\mathrm{a}}$

\begin{tabular}{lccc}
\hline & $\begin{array}{c}\text { Refeeding } \\
\text { Syndrome }\end{array}$ & Non-Refeeding & All Children \\
\hline $\mathbf{N}$ & 16 & 88 & 104 \\
\hline Oedema & $10(63)^{\mathrm{b}}$ & $56(64)$ & $66(63)$ \\
\hline MUAC, $<\mathbf{1 1 . 5} \mathbf{~ c m}$ & $8(50)$ & $43(49)$ & $51(49)$ \\
Visible wasting & $11(69)$ & $66(75)$ & $77(74)$ \\
\hline WHZ $<-3$ & $5(31)$ & $29(33)$ & $34(33)$ \\
\hline
\end{tabular}

Abbreviations: MUAC, mid-upper-arm-circumference; WHZ, weight for height Z-score.

${ }^{a}$ Values are expressed as No. (\%) with chi-square test used for comparison.

${ }^{\mathrm{b}}$ Significantly different from the non-refeeding group $(\mathrm{P}<0.05)$.

The majority of the children enrolled (63\%) had oedematous SAM, and this was true for children who acquired refeeding syndrome and those who did not. The majority of children, 46 of 66 (70\%) with oedematous SAM were HIV negative. Muscle wasting was visible in more than twothirds of all the children. Less than half of the children had a mid-upper-arm circumference of $<11.50 \mathrm{~cm}$. The mean mid-upper-arm-circumference was $12.02 \mathrm{~cm}$.

In relation to the medical complication of SAM, there were 90 (86\%) children in the study who developed one or more of the medical complications of SAM. Diarrhoea was observed in a significantly higher proportion (more than two-thirds) of children in the refeeding syndrome group compared with those in the group that did not de- 
velop refeeding syndrome. The incidence of hypokalaemia was significantly higher in the refeeding group in comparison to the non-refeeding group. Anaemia was noted in less than half of both the children enrolled in the study and in those who developed refeeding syndrome. However, the proportion of children with anaemia was considerably lower in the refeeding group than that in the group that did not develop refeeding syndrome. Shock affected a quarter (25\%) of children in the refeeding group and this proportion was significantly higher than that in the nonrefeeding group. Septicaemia occurred in less than a fifth of the children with refeeding syndrome. Weeping dermatosis was observed in 10 children, however this complication was shown to occur more frequently in children with refeeding syndrome than in those who did not develop refeeding syndrome. The medical complications of SAM among the enrolled children are summarized in Table 3.

Table 3. Medical Complications of $\mathrm{SAM}^{\mathrm{a}}$

\begin{tabular}{|c|c|c|c|}
\hline $\begin{array}{l}\text { Medical } \\
\text { Complication }\end{array}$ & $\begin{array}{l}\text { Refeeding } \\
\text { Syndrome }\end{array}$ & Non-Refeeding & $\begin{array}{l}\text { All Enrolled } \\
\text { Children }\end{array}$ \\
\hline $\mathbf{N}$ & 16 & 88 & 104 \\
\hline Diarrhoea & $13(81)^{b}$ & $37(42)$ & $50(48)$ \\
\hline Shock & $4(25)^{b}$ & $6(7)$ & $10(9.6)$ \\
\hline $\begin{array}{l}\text { Hypoglycaemia, } \\
\text { glucose }<2.6 \\
\text { mmol/L }\end{array}$ & 0 & $2(2)$ & $2(2)$ \\
\hline $\begin{array}{l}\text { Hypokalaemia, } \\
\text { potassium }<3 \\
\text { mmol/L }\end{array}$ & $13(81)^{\mathrm{b}}$ & $26(30)$ & $39(38)$ \\
\hline Anaemia & $5(31)^{b}$ & $42(48)$ & $47(45)$ \\
\hline Hypothermia & $1(6)$ & $12(14)$ & $13(13)$ \\
\hline $\begin{array}{l}\text { Hepatomegaly } \\
>4 \mathrm{~cm}\end{array}$ & $5(31)$ & $25(28)$ & $30(29)$ \\
\hline $\begin{array}{l}\text { Weeping } \\
\text { dermatoses }\end{array}$ & $2(12.5)^{\mathrm{b}}$ & $8(9)$ & $10(9.6)$ \\
\hline Septicaemia & $2(12.5)^{b}$ & $2(2)$ & $4(4)$ \\
\hline Mortality & $1(6)$ & $9(10)$ & $10(9.5)$ \\
\hline
\end{tabular}

${ }^{\mathrm{a}}$ Values are expressed as No. (\%).

${ }^{\mathrm{b}}$ Significantly different from the non-refeeding group $(\mathrm{P}$ value $<0.01)$ when using chi-square

The mean level of sodium among all enrolled children was similar to that observed in children who developed refeeding syndrome and those who did not develop it. Potassium and phosphate levels were significantly lower on admission in children with refeeding syndrome compared with those without the syndrome. Haemoglobin levels were comparable between the group of children with refeeding syndrome and the group that did not have the syndrome. Likewise, platelet counts were similar between the two groups of children.

The biochemical indices including electrolyte levels are summarized and compared by the development of refeeding syndrome among enrolled children in Table 4.

Blood samples for electrolytes were repeated on the 5 th day of hospitalization, the mean sodium levels on day 5 were similar to those measured on admission. On the other hand, serum phosphate levels were significantly lower on day 5 , compared with the levels on admission among children with refeeding syndrome.

\section{Discussion}

The objective of this study was to assess the incidence of refeeding syndrome in children less than 5 years of age with SAM and to assess the factors associated with the syndrome. The incidence of refeeding syndrome was found to be $15 \%$.

In terms of demographic characteristics, the youngest child in this study was approximately 5 months and the oldest was 50 months. This is in keeping with the wellknown fact that SAM is common in children in the age group of 6 months to 59 months $(9,19)$. In a study conducted in Kenya, the mean age was 20 months (range of 3 to 60 months) which is similar to the findings of this study (20). Among Brazilian children with SAM, a mean age of 20 months (range of 5 months to 7 years) was observed (21). In the current study, we noted that 58 (56\%) of the children were male. This slight male preponderance (not significant) among children with SAM was also noted by the authors of the Kenyan and Brazilian studies $(20,21)$.

The majority (63\%) of the children had oedematous SAM. This is in keeping with the fact that the oedematous SAM is much more prevalent in Central and Southern Africa compared with West Africa (22). Two studies conducted in Ghana noted a higher incidence of nonoedematous SAM ( $89 \%$ and $81 \%$ respectively) $(23,24)$. The difference could be as a result of the observation that nonoedematous SAM is more prevalent in Northern Ghana which is in West Africa (25). Another study performed in Uganda (26) had a similar incidence (64\%) of oedematous SAM as our study. Another South African study found a $62 \%$ incidence of oedematous SAM (27).

HIV infection occurred in 35 (33\%) of the children. In a study performed in Ghana the incidence of HIV among children with SAM was found to be $27 \%$ (4). In the study that we conducted, we noted that the majority of children with oedematous SAM were HIV negative. In contrast, the Ghanaian researchers observed that children with nonoedematous SAM were more likely to be HIV negative. The most plausible explanation for this difference is that the 
Table 4. Biochemical Indices of the Children in the Study on Admission and After 5 Days of Hospitalization

\begin{tabular}{|c|c|c|c|}
\hline & $\begin{array}{l}\text { Refeeding } \\
\text { Syndrome }\end{array}$ & $\begin{array}{l}\text { Non-Refeeding } \\
\text { Syndrome }\end{array}$ & All Children \\
\hline $\begin{array}{l}\text { Admission } \\
\text { Sodium, } \\
\text { mmol/L }\end{array}$ & $135.88 \pm 11.60$ & $134.82 \pm 5.24$ & $135 \pm 6.55$ \\
\hline $\begin{array}{l}\text { Repeat Sodium, } \\
\mathrm{mmol} / \mathrm{L}\end{array}$ & $136.75 \pm 4.29$ & $137.5 \pm 5.75$ & $137.13 \pm 5.53$ \\
\hline $\begin{array}{l}\text { Admission } \\
\text { Potassium, } \\
\text { mmol/L }\end{array}$ & $3.04 \pm 1.16^{\mathrm{a}}$ & $3.96 \pm 1.19$ & $3.81 \pm 1.23$ \\
\hline $\begin{array}{l}\text { Repeat } \\
\text { Potassium, } \\
\text { mmol/L }\end{array}$ & $4.69 \pm 0.99$ & $4.71 \pm 0.81$ & $4.72 \pm 0.83$ \\
\hline $\begin{array}{l}\text { Admission } \\
\text { Phosphate, } \\
\text { mmol/L }\end{array}$ & $1.14 \pm 0.39^{\mathrm{a}}$ & $1.42 \pm 0.69$ & $1.38 \pm 0.66$ \\
\hline $\begin{array}{l}\text { Repeat } \\
\text { Phosphate, } \\
\text { mmol/L }\end{array}$ & $0.65 \pm 0.28^{\mathrm{a}, \mathrm{b}}$ & $1.63 \pm 0.53$ & $1.48 \pm 0.61$ \\
\hline $\begin{array}{l}\text { Admission } \\
\text { Calcium, } \\
\text { mmol/L }\end{array}$ & $2.37 \pm 0.22$ & $2.41 \pm 0.21$ & $2.40 \pm 0.21$ \\
\hline $\begin{array}{l}\text { Repeat } \\
\text { Calcium, } \\
\text { mmol/L }\end{array}$ & $2.34 \pm 0.24^{\mathrm{a}}$ & $2.47 \pm 0.22$ & $2.45 \pm 0.23$ \\
\hline $\begin{array}{l}\text { Admission } \\
\text { Magnesium, } \\
\text { mmol/L }\end{array}$ & $1.07 \pm 0.34$ & $0.99 \pm 0.39$ & $1.01 \pm 0.34$ \\
\hline $\begin{array}{l}\text { Repeat } \\
\text { Magnesium, } \\
\text { mmol/L }\end{array}$ & $0.91 \pm 0.52^{\mathrm{a}}$ & $0.95 \pm 0.21$ & $0.95 \pm 0.27$ \\
\hline $\begin{array}{l}\text { Admission } \\
\text { Urea, } \mathrm{mmol} / \mathrm{L}\end{array}$ & $2.67 \pm 1.92$ & $2.95 \pm 3.93$ & $2.90 \pm 3.67$ \\
\hline $\begin{array}{l}\text { Repeat Urea, } \\
\mathrm{mmol} / \mathrm{L}\end{array}$ & $1.77 \pm 1.13^{\mathrm{a}}$ & $3.07 \pm 3.53$ & $2.61 \pm 1.92$ \\
\hline $\begin{array}{l}\text { Admission } \\
\text { Creatinine, } \\
\mu \mathrm{mol} / \mathrm{L}\end{array}$ & $44.81 \pm 13.92$ & $38.95 \pm 28.34$ & $39.84 \pm 26.67$ \\
\hline $\begin{array}{l}\text { Repeat } \\
\text { Creatinine, } \\
\mu \mathrm{mol} / \mathrm{L}\end{array}$ & $33.56 \pm 8.12$ & $39.10 \pm 39.95$ & $44.81 \pm 39.95$ \\
\hline $\begin{array}{l}\text { Haemoglobin } \\
\text { on admission, } \\
\text { g/dL }\end{array}$ & $10.05 \pm 1.17$ & $9.21 \pm 0.69$ & $9.35 \pm 1.77$ \\
\hline $\begin{array}{l}\text { C-Reactive } \\
\text { Protein on } \\
\text { admission, } \\
\text { mg/L }\end{array}$ & $57.12 \pm 98.69$ & $43.85 \pm 77.71$ & $45.9 \pm 80.89$ \\
\hline
\end{tabular}

prevalence of non-oedematous SAM has been noted to be higher in West Africa (which includes Ghana) compared with the prevalence in Southern Africa (22-24).
In the present study, only $33 \%$ of the children had a weight-for-height Z-score below -3 with a mean of less than -2.15 . This again could be attributed to oedematous SAM being more prevalent in Central and South Africa (22). A study performed in Dhaka, Bangladesh in 2015 reported a mean weight-for-height Z-score of $<-3.9$ (28). The mean weightfor-height Z-score was -2.15 among the children that we enrolled. The proportion of children with MUAC $<11.5 \mathrm{~cm}$ was $40 \%$ in our study with the mean MUAC being $12 \mathrm{~cm}$. Children from Ghana and Bangladesh have been reported to have lower MUAC measurements. Saaka et al. revealed that $67 \%$ of Ghanaian children with SAM had a MUAC below $11.5 \mathrm{~cm}$; there was a high prevalence of non-oedematous SAM among these children (23). In a study conducted in Dhaka, Bangladesh, children with SAM had a mean MUAC of $10.5 \mathrm{~cm}$ (28). This discrepancy in MUAC measurements may, partly, be a consequence of fact that the majority of children in the present study had oedematous SAM which is found more frequently in Central and Southern Africa.

The most commonly noted medical complications of SAM in our study were diarrhoea, shock, hypokalaemia, anaemia and hypothermia, hepatomegaly, and weeping dermatosis. This is in line with what was noted in a review article that summarized the medical complications of SAM where it was noted that approximately half of children with SAM had diarrhoea, with shock being present in about $10 \%$ of these children. A study conducted in Kenya among children with SAM reported that the incidence of diarrhoea was $49 \%$ (29). Hypokalaemia occurred in 38\% of the total children in our study and a similar incidence was shown in the Kenyan study. Hypoglycaemia manifested in $2 \%$ of children in our study, while among the Kenyan children it was noted in $13 \%$ of them (29). Our study was conducted in a tertiary hospital and it is probable that the treatment for hypoglycaemia may have been initiated in the referring district hospital prior to hospitalization in the tertiary hospital. On the other hand the Kenyan study was conducted in a district hospital (29).

The incidence of refeeding syndrome was found to be 15\%.The main electrolyte that was used for diagnosis was a phosphate level of $<1 \mathrm{mmol} / \mathrm{L}$ on day 5 of hospitalization. A study performed in Nairobi, Kenya assessed hypophosphatemia in malnourished children and recorded an incidence of refeeding syndrome of $90 \%$ on the fourth day of hospitalization (20). Maneses et al. evaluated refeeding syndrome in critically ill children who were in an intensive care unit and found an incidence of $61 \%$ (21). All the children that we enrolled were on cautious feeds with a low energy and low protein diet as per WHO guidelines $(30,31)$. The Kenyan study appears to have been using F100 as the form of initial feeding which could have predisposed to the higher incidence of refeeding syndrome. Indeed, cautious 
feeding (starting with F75) has been recommended for reducing refeeding syndrome (9).

Oedema was significantly associated with the refeeding syndrome, with $63 \%$ of children with refeeding syndrome having oedema. In a study conducted in Malawi, there was also a significant association between refeeding syndrome and oedema (32).

Refeeding syndrome in our study was associated with the following medical complications and electrolyte disturbances: diarrhoea, shock, hypokalaemia, anaemia, hepatomegaly above $4 \mathrm{~cm}$, weeping dermatosis, septicaemia, hypomagnesaemia, and hypocalcaemia. The above findings correlate with studies that assessed medical complications and electrolyte changes in both children and adults with refeeding syndrome $(16,32)$. A case series that reported on three malnourished Japanese children with sepsis revealed that all of them developed hypophosphataemia and hypocalcaemia on commencing nutritional support (33). A shortfall of our study was that a routine electrocardiogram was not performed on the children with refeeding syndrome due to limited resources.

The mortality among children with refeeding syndrome in our study was $6 \%$. This was slightly lower than that observed among adults who developed refeeding syndrome after experiencing prolonged starvation where the mortality rate was noted to be $10 \%$ (12). A mortality rate of $10 \%$ was observed in Malawian with SAM who developed refeeding syndrome (32).

This study revealed an incidence of refeeding syndrome of $15 \%$ in children younger than 5 years with SAM. Refeeding syndrome was significantly associated with certain medical complications and electrolyte abnormalities. These included diarrhoea, hypokalaemia, shock and weeping dermatosis, hypocalcaemia, and hypomagnesaemia. The mortality rate observed in children with refeeding syndrome was $6 \%$.

\subsection{Conclusions}

The complication of refeeding syndrome is a major problem that occurs with the reintroduction of feeding in children with severe acute malnutrition. This detrimental complication can be avoided by practices that promote cautious feeding, and as well, clinicians being vigilant in detecting the complication in all children with severe acute malnutrition.

\section{Supplementary Material}

Supplementary material(s) is available here.

\section{Acknowledgments}

The researchers appreciate the collaboration and cooperation of all the parents of the children enrolled in this study. The contribution of the doctors, nurses and other health personnel of Dr George Mukhari Academic Hospital in the management of the patients is highly appreciated. We would also like to thank our families for their continued loving support.

\section{References}

1. WHO. Guideline: Updates on the management of severe acute malnutrition in infants and children. Geneva: World Health Organization; 2013.

2. Irena AH, Mwambazi M, Mulenga V. Diarrhea is a major killer of children with severe acute malnutrition admitted to inpatient setup in Lusaka, Zambia. Nutr J. 2011;10:110. doi: 10.1186/1475-2891-10-110. [PubMed: 21989455].

3. Bachmann MO. Cost-effectiveness of community-based treatment of severe acute malnutrition in children. Expert Rev Pharmacoecon Outcomes Res. 2010;10(5):605-12. doi: 10.1586/erp.10.54. [PubMed: 20950075].

4. Munthali T, Jacobs C, Sitali L, Dambe R, Michelo C. Mortality and morbidity patterns in under-five children with severe acute malnutrition (SAM) in Zambia: a five-year retrospective review of hospitalbased records (2009-2013). Arch Public Health. 2015;73(1):23. doi: 10.1186/s13690-015-0072-1. [PubMed: 25937927].

5. DOH . District Health Information System in the Department of Health, 2001-2010. ; 2010.

6. Statistics South Africa (STATS SA) . Quarterly Labour Force Survey, 2009-2010. ; 2010.

7. National Department of Health $(\mathrm{NDoH})$. Integrated management of children with acute malnutrition in South Africa: Operational guidelines. ; 2015.

8. Kliegman RM. Nutrition, Food security and Health. In: Kliegman RM, editor. Nelson Textbook of Pediatrics. Philedalphia: Saunders Elsevier; 2016. pp. 295-306.

9. Grover Z, Ee LC. Protein energy malnutrition. Pediatr Clin North Am. 2009;56(5):1055-68. doi: 10.1016/j.pcl.2009.07.001. [PubMed: 19931063].

10. Fuentebella J, Kerner JA. Refeeding syndrome. Pediatr Clin North Am. 2009;56(5):1201-10. doi: 10.1016/j.pcl.2009.06.006. [PubMed: 19931071].

11. Mehanna HM, Moledina J, Travis J. Refeeding syndrome: what it is, and how to prevent and treat it. BMJ. 2008;336(7659):1495-8. doi: 10.1136/bmj.a301. [PubMed: 18583681].

12. Vignaud M, Constantin JM, Ruivard M, Villemeyre-Plane M, Futier E, Bazin JE, et al. Refeeding syndrome influences outcome of anorexia nervosa patients in intensive care unit: an observational study. Crit Care. 2010;14(5):R172. doi: 10.1186/Cc9274. [PubMed: 20920160].

13. Ornstein RM, Golden NH, Jacobson MS, Shenker IR. Hypophosphatemia during nutritional rehabilitation in anorexia nervosa: implications for refeeding and monitoring. I Adolesc Health. 2003;32(1):83-8. [PubMed: 12507806].

14. Agarwal J, Poddar U, Yachha SK, Srivastava A. Refeeding syndrome in children in developing countries who have celiac disease. J Pediatr Gastroenterol Nutr. 2012;54(4):521-4. doi: 10.1097/MPG.0b013e318242fe1d. [PubMed: 22157921].

15. Kraft MD, Btaiche IF, Sacks GS. Review of the refeeding syndrome. Nutr Clin Pract. 2005;20(6):625-33. doi: 10.1177/0115426505020006625. [PubMed: 16306300]. 
16. Byrnes MC, Stangenes J. Refeeding in the ICU: an adult and pediatric problem. Curr Opin Clin Nutr Metab Care. 2011;14(2):186-92. doi: 10.1097/MCO.ob013e328341ed93. [PubMed: 21102317].

17. Unicef . The state of the world's children 2012: children in an urban world. eSocialSciences; 2012.

18. Cloete J. Management of severe acute malnutrition. S Afr Med J. 2015;105(7):605-6. [PubMed: 26447242].

19. Binns P, Dale N, Hoq M, Banda C, Myatt M. Relationship between mid upper arm circumference and weight changes in children aged 6-59 months. Arch Public Health. 2015;73:54. doi: 10.1186/s13690-015-0103-y. [PubMed: 26693279].

20. Kimutai D, Maleche-Obimbo E, Kamenwa R, Murila F. Hypophosphataemia in children under five years with kwashiorkor and marasmic kwashiorkor. East Afr Med J. 2009;86(7):330-6. [PubMed: 20499782].

21. Santana e Meneses JF, Leite HP, de Carvalho WB, Lopes EJ. Hypophosphatemia in critically ill children: prevalence and associated risk factors. Pediatr Crit Care Med. 2009;10(2):234-8. doi: 10.1097/PCC.ob013e3181937042. [PubMed: 19057439].

22. Frison S, Checchi F, Kerac M. Omitting edema measurement: how much acute malnutrition are we missing?. Am J Clin Nutr. 2015;102(5):1176-81. doi: 10.3945/ajcn.115.108282. [PubMed: 26377162].

23. Saaka M, Osman SM, Amponsem A, Ziem JB, Abdul-Mumin A, Akanbong P, et al. Treatment Outcome of Severe Acute Malnutrition Cases at the Tamale Teaching Hospital. J Nutr Metab. 2015;2015:641784. doi: 10.1155/2015/641784. [PubMed: 26064678].

24. Asafo-Agyei SB, Antwi S, Nguah SB. HIV infection in severely malnourished children in Kumasi, Ghana: a cross-sectional prospective study. BMC Pediatr. 2013;13:181. doi: 10.1186/1471-2431-13-181. [PubMed: 24206638].

25. Culyba MJ, Hwang Y, Hu JY, Minkah N, Ocwieja KE, Bushman FD. Metal cofactors in the structure and activity of the fowlpox resolvase. Mol Biol. 2010;399(1):182-95. doi:10.1016/j.jmb.2010.03.054. [PubMed 20380839].
26. Rytter MJ, Namusoke H, Babirekere-Iriso E, Kaestel P, Girma T, Christensen VB, et al. Social, dietary and clinical correlates of oedema in children with severe acute malnutrition: a cross-sectional study. BMC Pediatr. 2015;15:25. doi: 10.1186/s12887-015-0341-8. [PubMed: 25885808].

27. Saloojee H, De Maayer T, Garenne ML, Kahn K. What's new? Investigating risk factors for severe childhood malnutrition in a high HIV prevalence South African setting. Scand J Public Health Suppl. 2007;69:96106. doi: 10.1080/14034950701356435. [PubMed: 17676510].

28. Chisti MJ, Salam MA, Bardhan PK, Faruque AS, Shahid AS, Shahunja KM, et al. Treatment Failure and Mortality amongst Children with Severe Acute Malnutrition Presenting with Cough or Respiratory Difficulty and Radiological Pneumonia. PLoS One. 2015;10(10):e0140327. doi: 10.1371/journal.pone.0140327. [PubMed: 26451603].

29. Talbert A, Thuo N, Karisa J, Chesaro C, Ohuma E, Ignas J, et al. Diarrhoea complicating severe acute malnutrition in Kenyan children: a prospective descriptive study of risk factors and outcome. PLoS One. 2012;7(6):e38321. doi: 10.1371/journal.pone.0038321. [PubMed: 22675542].

30. Lenters L, Wazny K, Bhutta ZA. Management of Severe and Moderate Acute Malnutrition in Children. Toronto, Canada: Centre for Global Child Health, The Hospital for Sick Children; 2016.

31. Bernal C, Velasquez C, Alcaraz G, Botero J. Treatment of severe malnutrition in children: experience in implementing the World Health Organization guidelines in Turbo, Colombia. J Pediatr Gastroenterol Nutr. 2008;46(3):322-8. doi:10.1097/MPG.0b013e318156c2c3. [PubMed: 18376252].

32. Manary MJ, Hart CA, Whyte MP. Severe hypophosphatemia in children with kwashiorkor is associated with increased mortality. J Pediatr. 1998;133(6):789-91. [PubMed: 9842046].

33. Yoshimatsu S, Chisti MJ, Hossain MI, Islam MM, Fukushima T, Wagatsuma Y, et al. Hypophosphataemia among severely-malnourished children: case series. J Health Popul Nutr. 2012;30(4):491-4. [PubMed: 23304916]. 